\title{
Performance of heat pump system for water heating in European climate
}

\author{
Yauheni Kachalouski ${ }^{1, *}$, Matuška Tomáš ${ }^{2}$ \\ ${ }^{1}$ Department of Environmental Engineering Faculty of Mechanical Engineering, Czech Technical University in Prague, Technická 4, \\ 16607, Prague, Czech Republic \\ ${ }^{2}$ University Centre for Energy Efficient Buildings, Czech Technical University in Prague, Třinecká 1024, 27343 Buštěhrad, Czech \\ Republic
}

\begin{abstract}
A performance of air-to-water and brine-to-water heat pump for domestic hot water preparation was analyzed in different climates of Europe. Air-source heat pumps are widely used energy source for domestic applications with low operation costs. Their system SPF was found at level of 3.0 for domestic hot water preparation for medium latitudes in Europe. Investigations on the ground-source heat pump performance show their average $S P F$ are close to air-source technology.
\end{abstract}

\section{Introduction}

Heat pumps are widely used as an ambient heat transformer for space heating $(\mathrm{SH})$ and domestic hot water (DHW) preparation in Europe [1], however a lot of countries have only small share of installed heat pump power, e.g. such as Czech Republic. But general tendency in the market growth can be seen from statistics and reports [1]. Overall, the industry is optimistic for a continued market growth and more markets we return to growth in future. Moreover, according to the field measurements the overall performance of heat pumps in service is increasing [2]. This takes place in connection with new heat pump installations. It was investigated that on average the airsource heat pumps perform with a system performance factor $(S P F)$ in the range of $2.2-4.2$ with an average value of 3.1, and at the same time the ground-source heat pumps perform with $S P F$ in the range of 3.0 - 5.4 with the average value of 4.3 [2]. The numbers indicated above are for newly built single-family dwellings. Furthermore, European standard on design of heat pump heating systems specifies the minimum and target values of heat pump performance, i.e. for air-source heat pump minimum and target $S P F$ values are 2.3 and 2.8, respectively and 3.0 and 3.5 for the ground-source heat pumps with application for DHW and SH.

Thus, the study of air- and ground-source heat pump performance for DHW preparation under different climate conditions in Europe was carried out. The results demonstrate the scope of heat pump applicability for DHW preparation in European countries in regard to the standard [3].

\section{Analysis of water heating heat pump system}

\footnotetext{
* Corresponding author: Yauheni.Kachalouski@,fs.cvut.cz
}

Use of air source pump (ASHP) and ground source heat pump (GSHP) for DHW preparation has been analyzed for single family house with 4 persons with total hot water demand of 2061 at $45{ }^{\circ} \mathrm{C}$. Analysis has been performed by means of simulations using TRNSYS software [4]. Analyzed system for DHW preparation consists of heat pump, hot water storage (TES), circulating pumps, controller and back-up heater (see Figure 1).

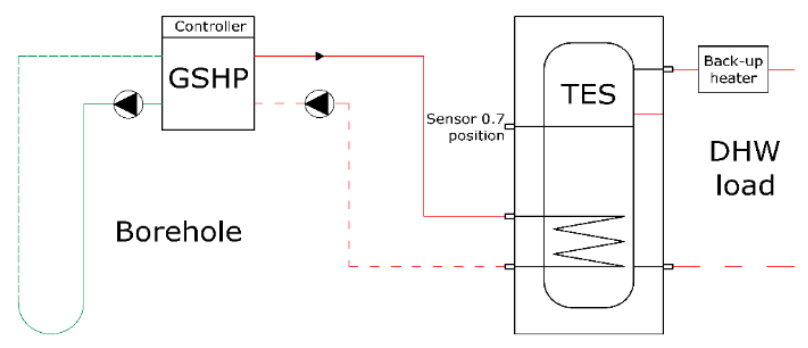

Fig. 1. Scheme of water heating ground-source heat pump system.

The heat pumps of both types have been sized to allow the hot water preparation and there were considered specific products available on the market. ASHP has the heat output $6.6 \mathrm{~kW}$ and $C O P=3.1$ at $\mathrm{A} 2 / \mathrm{W} 35$ conditions, at the same time GSHP has a heat output $5.8 \mathrm{~kW}$ and $C O P=4.5$ at $\mathrm{B} 0 / \mathrm{W} 35$ conditions. The performance of heat pumps has been modelled with use of bi-quadratic curve fits for the heat output and electric power input. The curve-fit parameters were obtained for commercially available heat pumps by least-square fitting from manufacturer's data [5] (see Figure 2). For the modelling of the heat pump performance, several restrictions have been imposed on heat pump operation, such as maximum 
and minimum condenser and evaporator operating temperatures and minimal standby time between its start and stop (10 $\mathrm{min})$.

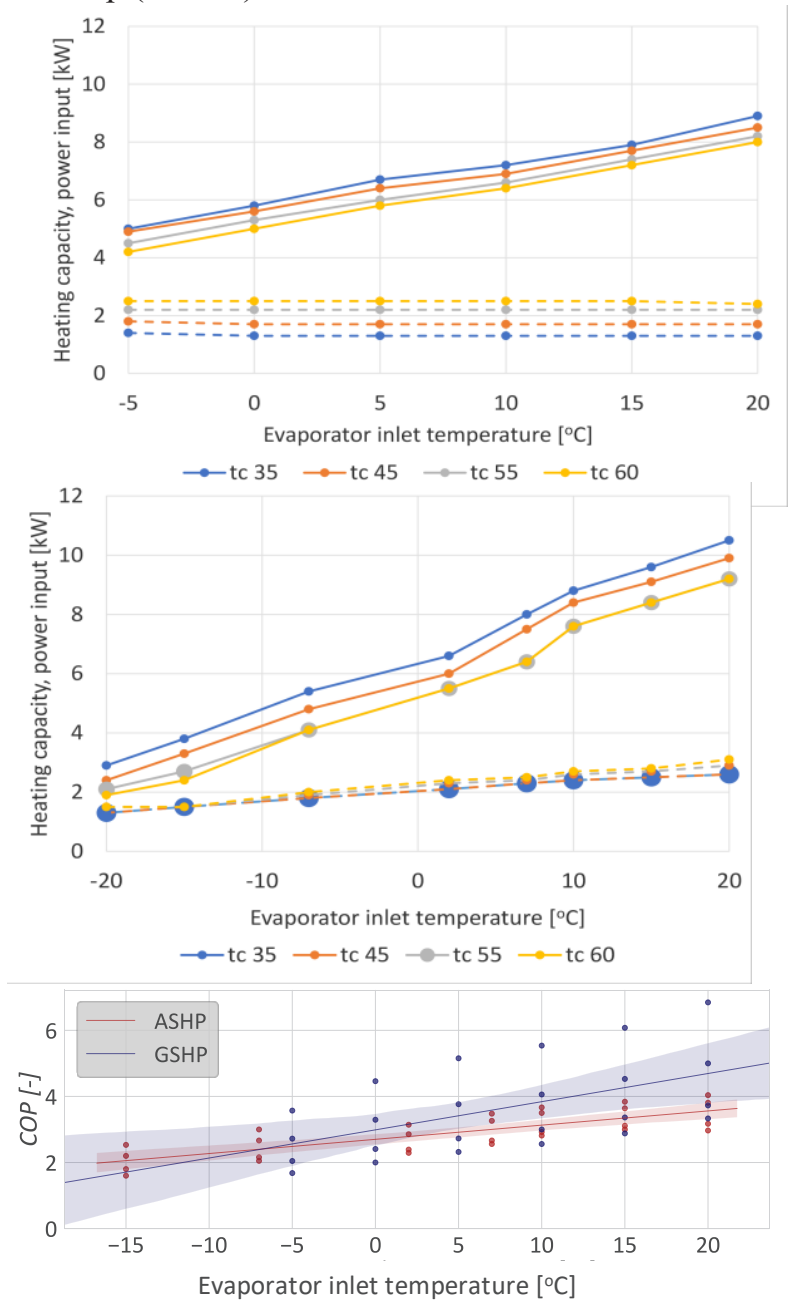

Fig. 2. Heat output, compressor power input and $C O P$ for airsource and ground-source heat pumps

The volume of the hot water storage is considered 2001. To transfer the heat from the heat pump into water the immersed tube heat exchanger is applied. DHW tank has been modelled as the stratified fluid storage tank with internal heat exchanger known as type 340 [6]. The $U A$ value of heat exchanger is $640 \mathrm{~W} / \mathrm{K}$ and it is considered as a function of temperature difference between fluid in the heat exchanger and in the storage. The heat loss of the DHW tank is characterized by overall UA-value of $1.58 \mathrm{~W} / \mathrm{K}$, distributed by $23 \%$ for top heat loss, $70 \%$ to wall heat loss and $7 \%$ to bottom heat loss. The whole storage volume is divided into 30 completely mixed volume segments. The temperature sensor is placed at the 0.7 of relative height of the total tank height. Set-point temperature of sensor in the storage tank for hot water preparation control is $50{ }^{\circ} \mathrm{C}$ with a deadband of $\pm 2 \mathrm{~K}$.

Ground-source heat pump is equipped with single Utube borehole of $68 \mathrm{~m}$ depth. Here, to simplify the parametric analysis the sizing has been used universally for all cases. The model of borehole used in simulations is type 557 of TESS library for TRNSYS [7]. The ground and fill material thermal conductivity was set to $2 \mathrm{~W} / \mathrm{m}$.K.

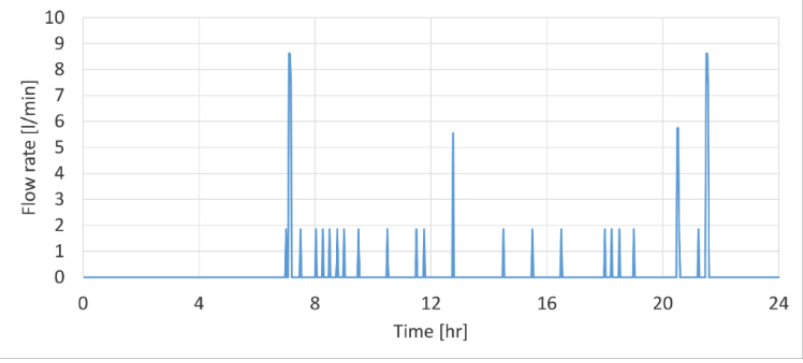

Fig. 3. DHW load profile adopted from M profile [8].

To model a realistic hot water load with morning/evening peaks and night load profile $\mathrm{M}$ has been taken from EU Commission Regulation 814/2013 on ecodesign of water heaters [8]. Daily profile corresponding to the hot water consumption of single family of 4 persons is shown in Figure 3. However, the load profile $\mathrm{M}$ was adjusted from delivering temperature of $55^{\circ} \mathrm{C}$ to $45^{\circ} \mathrm{C}$ temperature of water intake keeping the same amount of energy consumed (see Figure 2). Reduction of the hot water temperature has been applied as more realistic requirement when using heat pumps in single-family houses.

The heat pump system has been considered in different climate locations throughout the Europe. Hourly climate data for each location has been obtained from meteorological database Meteonorm [4]. Data sets for 358 locations in the Europe (see Figure 4) have been selected for the analysis. The northernmost location is Barentsburg, Norway (GPS 78.1, 14.2), the southernmost location is Funchal, Portugal (GPS 32.6, -16.9). Cold water mains temperature has been derived by using the following algorithm adopted from [9]:

$$
\mathrm{t}_{\text {mains }}=\left(\bar{t}_{\text {amb }}+o f f\right)+r\left(\frac{t_{a m b, \max }}{2}\right) \sin \left(\frac{360}{365}(\text { day }-15-\text { lag })-90\right)
$$

where is

$\bar{t}_{a m b}, t_{a m b, \max }$ average and maximum ambient temperature $\left[{ }^{\circ} \mathrm{C}\right]$;

off, r, lag fitting coefficients [-], offset, ratio and lag values were obtained by fitting data compiled by Abrams and Shedd and Sandia Labs [9]; 


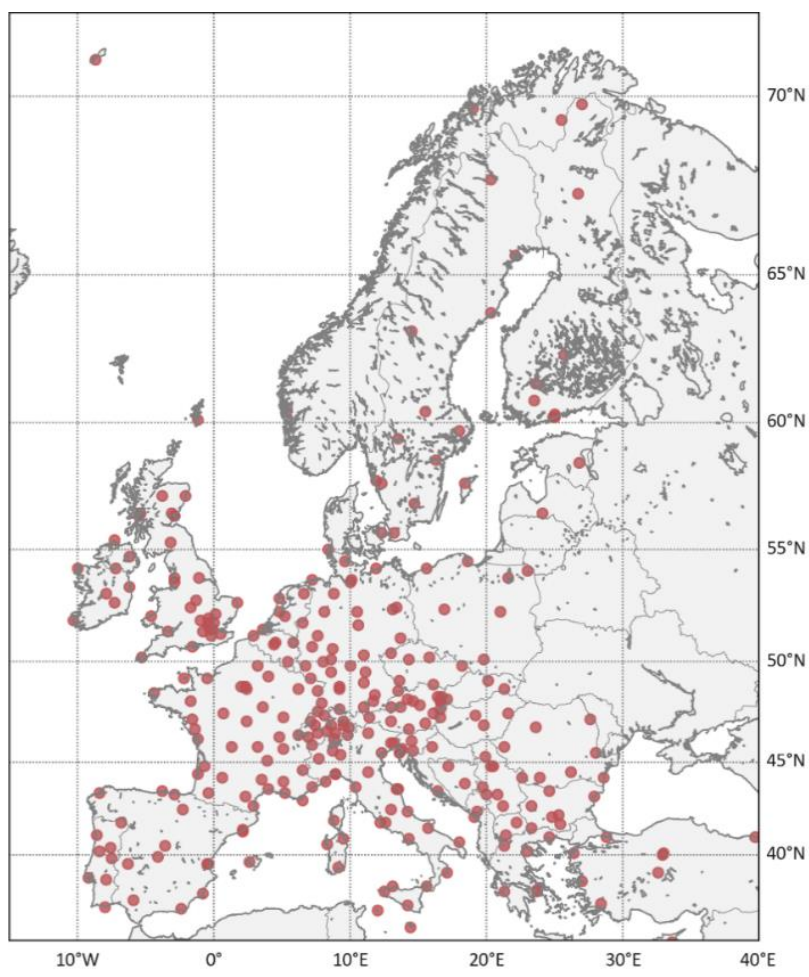

Fig. 4. Locations considered in the simulations.

The operation conditions of hot water preparation by air source heat pump: ambient air temperature and cold water temperature are influenced not only by geographical latitude but also altitude (see Figure 5). Data of high altitude around latitude value of $48^{\circ}$ is for locations in Alps mountains. The fitting coefficients proposed by Abrams and Shedd in Equation 1 lead the water mains temperatures decrease below $0^{\circ} \mathrm{C}$ in high latitudes, hence it was suggested to limit water mains temperature down to $4^{\circ} \mathrm{C}$ in these latitudes, which is seen in Figure 5.

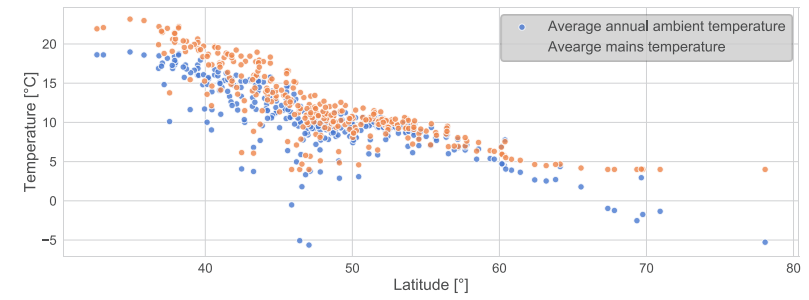

Fig. 5. Average annual ambient and mains temperature.

The extensive number of numerical simulations were performed in TRNSYS software [4] which was controlled over the Python script. This approach allows to generate newly compounded TRNSYS input file (*.dck-file) containing all the boundary conditions for each simulation.

\section{Results}

Heat demand for hot water preparation differs in different locations (Figure 6) due to the water mains temperature differs throughout the year (Figure 5) influencing DHW energy delivered to the consumer. Thus, heat demand increases with latitude when moving to the north or with the altitude of the location. It is about double in the mountain areas or northern part of Europe than it is in the southern Europe.

Moving from south to north increasing latitude of the location the total system electrical energy consumption (which includes electrical consumption of heat pump, circulation pump and back-up heater) increases. Again, the spike between $45^{\circ}$ and $50^{\circ}$ latitude indicates high altitude of given sites in mountains characterized by significantly higher heat demand for hot water preparation (see Figure 6) and extreme conditions for heat pump operation. System total electrical consumption in this mountain area is thus approximately 1.5 times higher than it is in the same latitude location but with low altitude $(1500 \mathrm{kWh}$ versus $1000 \mathrm{kWh})$.

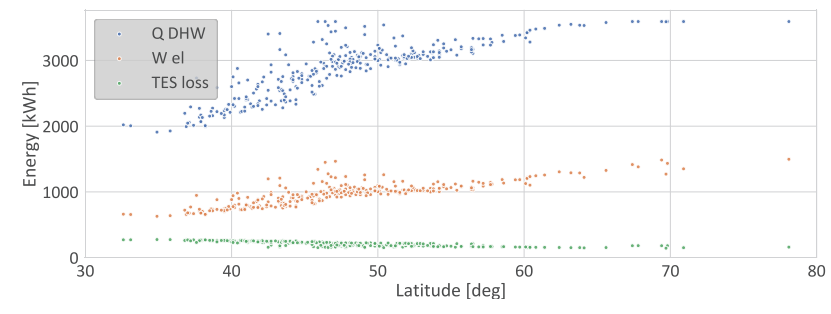

Fig. 6. DHW heat demand, system electrical energy consumption and TES heat loss for different locations (latitude) for ASHP.

In general air-source and ground-source heat pump system simulations resulted in similar system performance for given location. Figure 6 provides simulations results of DHW heat demand, system electricity consumption and storage tank heat loss for air-source heat pump only. Due to these values are barely distinguishable from those obtained for the ground-source heat pump, to investigate key difference in performance of two types of heat pumps the $S P F$ values were evaluate alone (Figure 7).

Significant correlation was identified between system performance and the boundary conditions the heat pump was exposed to. By exploiting overall system seasonal performance factor $(S P F)$ the heat pump system can be evaluated as follows:

$$
S P F=\frac{Q_{D H W}}{W_{e l, h p}+W_{e l, a u x}+W_{e l, b u}}
$$

where is

QDHw heat delivered to hot water load [kWh];

$\mathrm{W}_{\text {el,hp }} \quad$ electricity consumed by heat pump [kWh];

$\mathrm{W}_{\mathrm{el}, \mathrm{aux}}$ electricity consumed by circulating pump

$\mathrm{W}_{\text {el,bu }} \quad$ electricity consumed by back-up heater [kWh].

The efficiency of heat pump described as coefficient of performance $C O P$. The annual $C O P$ has been calculated according to the Equation (2) as follows:

where is

$$
C O P=\frac{Q_{c}}{W_{e l, h p}}
$$

$\mathrm{Q}_{\mathrm{c}} \quad$ condenser heat output $[\mathrm{kWh}]$;

$\mathrm{W}_{\mathrm{el}, \mathrm{hp}} \quad$ electricity consumed by heat pump [kWh]. 

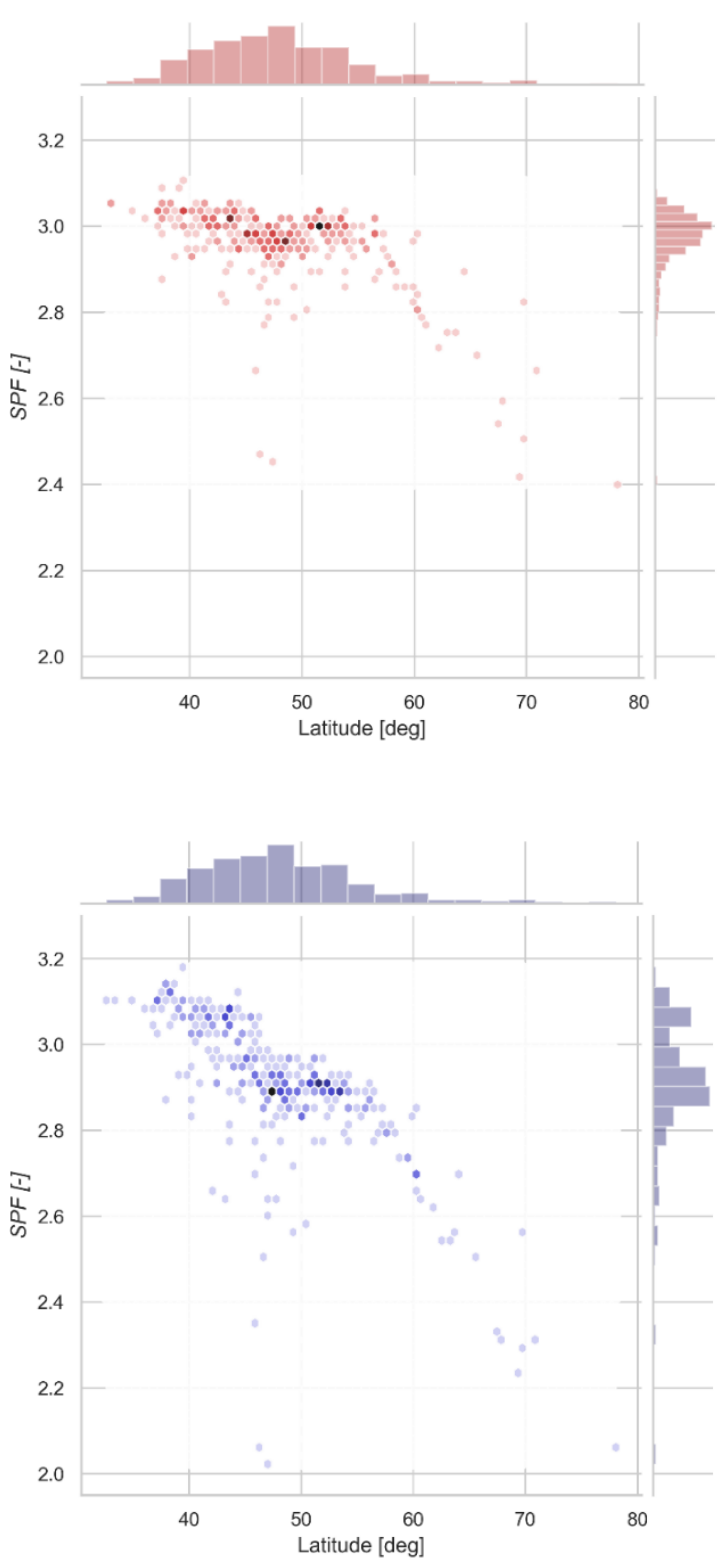

Fig. 7. $S P F$ of heat pump system in different locations: top ASHP, bottom - GSHP.

Figure 7 reflects that seasonal performance factor $S P F$ of ASHP at considered locations is close to normal distribution with peak in value 3.0. On the other hand, GSHP has two peaks for SPF near the 3.1 and 2.9 values. Also, one can see that GSHP outperforms ASHP in warm climate (low latitudes) but has a bit worse efficiency in mid- and high latitudes (mid- and cold climate). This fact can be good explained from the Figure 3 that reveals the heat pump coefficients of performance, and the GSHP has a steeper global regression line of $C O P$.

As it is known the heat pump performance is dependent on the condensing and evaporating temperatures, hence in case of air source heat pump technology on the condenser supply temperature (which is influenced by water mains temperature) and on the ambient temperature. Thus, the only parameters that have a key influence on the heat pump $C O P$ and $S P F$ are the ambient temperature and water mains temperature.
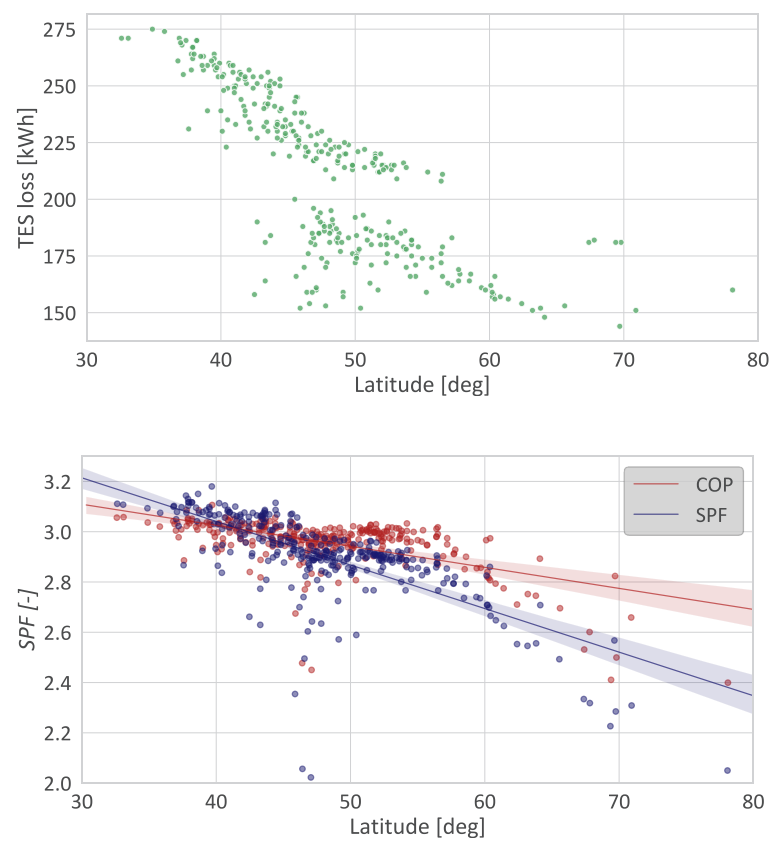

Fig. 8. COP and SPF (top) and DHW tank heat loss (bottom) of ASHP in different locations

The heat pump system efficiency decreases due to the operation under low inlet temperatures to the evaporator in high latitudes and/or altitudes. System $S P F$ in all locations has less obvious trend than the trend for $C O P$ of the heat pump, but it is also decreasing with the latitude (see Figure 8). It is given by the fact that the heat loss of hot water storage tank is covered by heat pump and thus included in surplus electricity consumption and reflected in worsening the system parameter $S P F$, while $C O P$ characterizes only the efficiency of the heat pump alone. The heat loss from the hot water storage tank to the surroundings is also varying with the location, it is higher in warmer climate than it is in colder climate. It seems surprising at least for first sight, however it is logic and it is followed by detailed explanation.

The heat loss of storage tank to the surroundings occurs due to temperature difference between the storage tank volume and the surroundings (technical room where storage tank is placed), as follows:

$$
\dot{Q}_{\text {loss }}=U A\left(t_{S T}-\bar{t}_{r}\right)
$$

where is

$U \quad$ overall heat transfer coefficient of the storage tank $\left[\mathrm{W} /\left(\mathrm{m}^{2} \mathrm{~K}\right)\right]$;

A surface area of the storage tank envelope $\left[\mathrm{m}^{2}\right]$;

$t_{S T} \quad$ mean storage tank temperature $\left[{ }^{\circ} \mathrm{C}\right]$;

$\bar{t}_{r} \quad$ room temperature $\left[{ }^{\circ} \mathrm{C}\right]$, for the simulations considered to be constant and equal to $20^{\circ} \mathrm{C}$.

As one can see from the Equation 3 the higher the temperature difference between DHW tank and the surroundings, the higher heat loss rate under constant UAvalue. Considering a stratification behavior of the DHW tank and that the temperature sensor is installed at the top 
part of the tank (at $70 \%$ of the tank height), the bottom part of the DHW tank after finished charging cycle is usually filled with the cold water and it is not mixed with the top part, due to the thermocline. Thus, the top part of DHW tank is heated up to the desired set temperature $50{ }^{\circ} \mathrm{C}$, however the bottom part remains at low temperature close to the temperature of cold water. Since the set temperature of the DHW tank is the same in all the simulations, temperature of the cold water mains has the huge impact on the mean tank temperature. Therefore, the lower the water mains temperature is the lower the mean tank temperature $t_{\mathrm{ST}}$ finally will be. Higher temperature of water mains in low latitude locations then results in higher heat loss of DHW system (see Figure 8).

To show the influence of water mains temperature on heat loss and further to seasonal efficiency expressed by $S P F$, three locations have been selected representing warm climate (Athens, Greece), medium climate (Strasbourg, France) and cold climate (Helsinki, Finland).

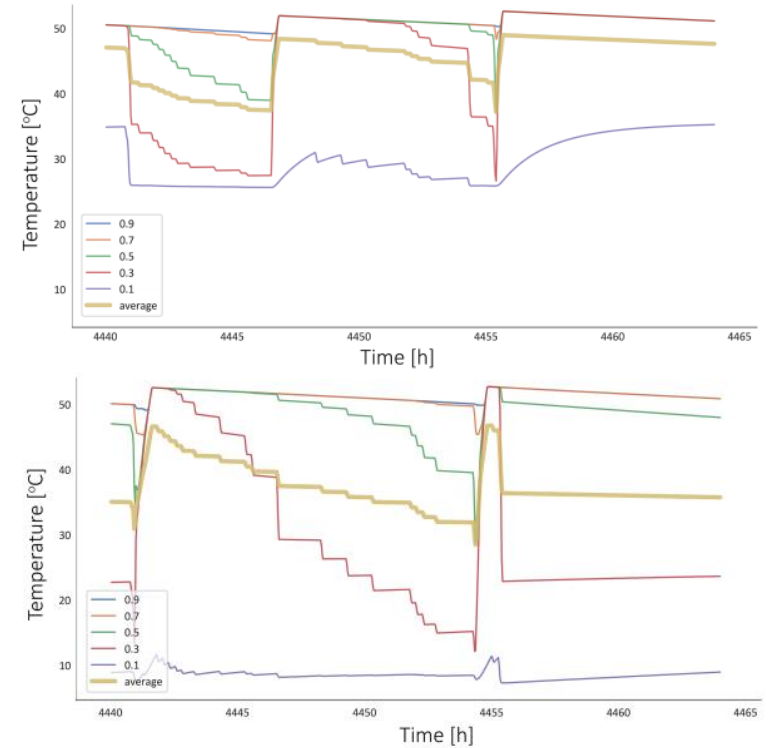

Fig. 9 System one-day simulation in Athens (upper) and Helsinki (lower) climate.

Simulation of one-day period is compared for significantly distinct locations Athens and Helsinki. Temperature in 5 positions of DHW tank relative height $(0.9$ / $0.7 / 0.5 / 0.3 / 0.1)$ has been monitored during the simulations. As it can be seen from Figure 10 the heat pump operates before large tapping in the evening $(21 \mathrm{~h})$ for cold climate causing mean DHW tank temperature to drop after this tapping occurred, though monitoring temperature remains high enough for the heat pump controller not to start DHW tank charging again. Since there is no tapping during the night time the mean DHW tank temperature is lower in comparison with the warmer climate (Figure 10), where the heat pump operates even after last tapping in the day keeping the DHW tank charged and at high temperature.

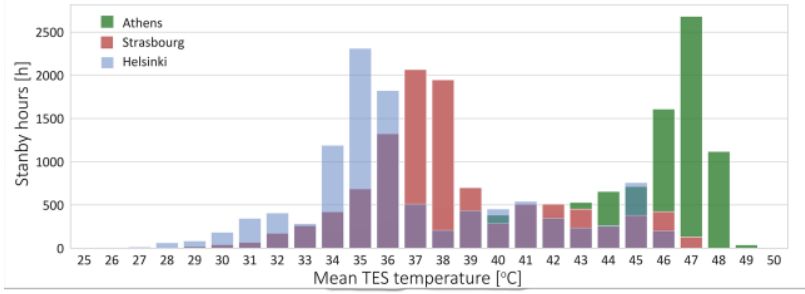

Fig. 10 DHW tank standby hours versus different mean storage temperatures in three climate locations.

As it can be seen from Figure 9, mean water temperature in the tank in cold climate is lower compared with southern climate, this consequently causes lower rate of heat loss to the surroundings $\left(20^{\circ} \mathrm{C}\right)$ in colder climate (Helsinki) compared to warmer climate (Athens).

Further, for the Helsinki climate simulation (Figure 10) the bottom part of storage tank is colder than surroundings leading to the heat flow direction to be from surrounding to the tank, i.e. bottom part of the storage tank obtains heat gains. This phenomenon has in its turn an influence on DHW tank heat loss at given location. Figure 10 also reveals a strong temperature stratification in case of colder water inlet to the DHW tank, which is no longer take place in warm climate (sensor 0.1 ).

The observed bias of TES loss can be satisfactorily explained with Figure 10 presenting TES standby hours at each mean temperature in three climates. Selected system setup (component parameters, control settings, etc.) often results in higher mean temperature of the storage in warm climate (Athens) compared to cold climate (Helsinki).

As discussed and concluded above, GSHP has a steeper regression line of $C O P$ (see Figure 3), nevertheless on the other hand system $S P F$ is greater for ASHP than GSHP (Figure 7). To shed light on this discrepancy Figure 11 compares GSHP evaporator inlet temperatures for three climates. If one compares average ambient air temperature, i.e. evaporator inlet temperature for ASHP, with average borehole outlet temperatures, i.e. evaporator inlet temperature for GSHP, for the same location GSHP outperforms ASHP only in warm climate, despite the fact the ambient air temperature Athens is $17.6^{\circ} \mathrm{C}$, while outlet of borehole keeps at level of $7.5^{\circ} \mathrm{C}$ (Figure 11). Temperature values for given locations are given in the Table 1.

Table 1. Average evaporator inlet temperatures for ASHP and GSHP for three climate locations.

\begin{tabular}{|l|c|c|}
\hline $\begin{array}{l}\text { Heat pump } \\
\text { technology / } \\
\text { location }\end{array}$ & $\begin{array}{c}\text { Average ambient air } \\
\text { temperature (ASHP } \\
\text { evaporator inlet) }\end{array}$ & $\begin{array}{c}\text { Average borehole } \\
\text { outlet temperature } \\
\text { (GSHP evaporator } \\
\text { inlet) }\end{array}$ \\
\hline Athens & 17.6 & 7.5 \\
\hline Strasbourg & 9.8 & 1.5 \\
\hline Helsinki & 4.5 & -2.5 \\
\hline
\end{tabular}



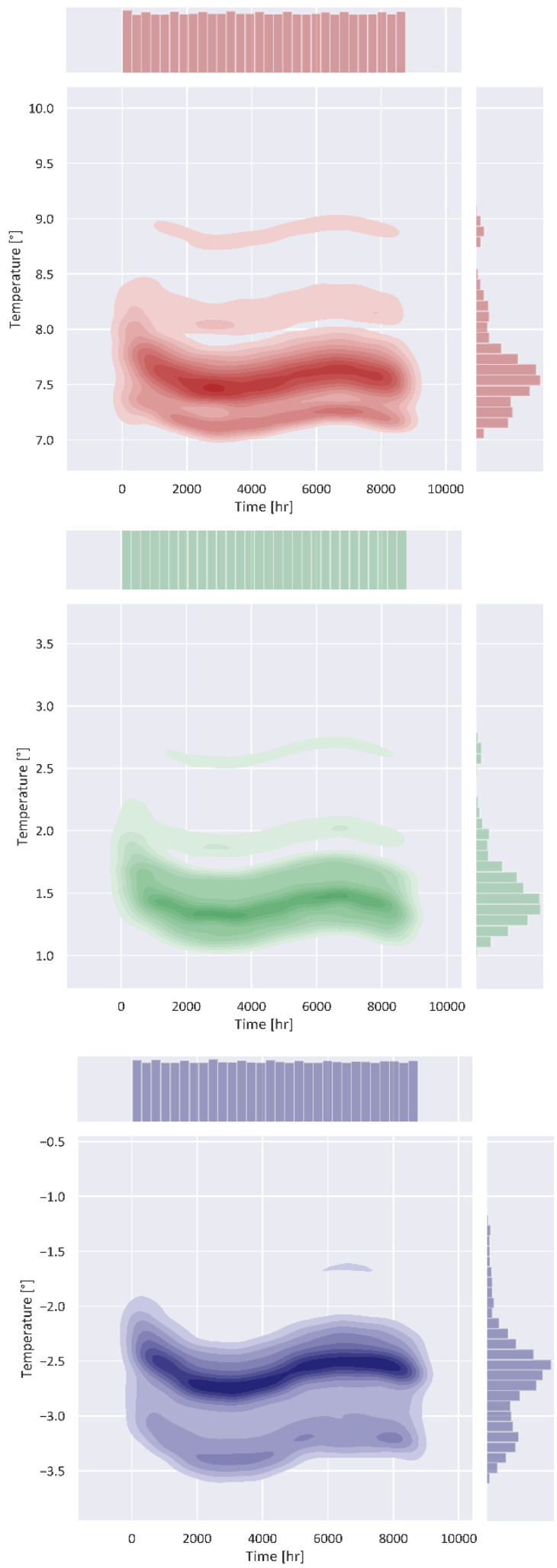

Fig. 11 GSHP evaporator inlet temperature: top - Athens, center - Strasbourg, bottom - Helsinki climate.

\section{Conclusions}

The system analysis shows that heat pump performance for hot water preparation is strongly dependent on the climate, i.e. ambient temperature and temperature of the water mains. The highest SPF reached by the ASHP during this study was around 3.1, the lowest -2.4 , however the GSHP simulations resulted in $S P F$ of 3.2 - 2.0 range. Average $S P F$ values were found to be 3.0 and 2.9 for ASHP and GSHP, respectively. Average values are in good correspondence with target values of the standard [3] which were given in the introduction.

Though this study was limited to the same setup for all locations it demonstrated that such system (air- and ground-source performance does not drop lower than minimum value of 2.3 , mainly due to lower DHW water intake temperature of $45^{\circ} \mathrm{C}$ versus widely used $55^{\circ} \mathrm{C}$ ). It is worth to mention that the results obtained are in good compliance with the measurements of real installations [2].

The authors would like to acknowledge the financial support received for this research from NPU (National Sustainability Program I, project No. LO1605).

\section{References}

1. Author, European Heat Pump Market and Statistics Report 2015 Executive Summary. pp. 7-10, EHPA, 2015.

2. M. Miara, "Efficiency of Heat Pumps in Real Operating Conditions - Results of three Monitoring Campaigns in Germany," REHVA Eur. HVAC J., vol. 51, pp. 5-12, 2014.

3. EN 15450 Heating systems in buildings - Design of heat pump heating systems, CEN, 2008.

4. U. of W.--M. S. E. Laboratory, TRNSYS, a transient simulation program. Madison, Wis.: The Laboratory, 1975., 1975.

5. E. Jones, T. Oliphant, P. Peterson, and others, " $\{$ SciPy $\}$ : Open source scientific tools for $\{$ Python\}."

6. H. Drück and D.-I. H. habil Müller-Steinhagen Pfaffenwaldring, "MULTIPORT Store -Model for TRNSYS Stratified fluid storage tank with four internal heat exchangers, ten connections for direct charge and discharge and an internal electrical heater Type 340," p. 27, 2006.

7. G. Hellström, "Duct Ground Heat Storage Model, Manual for Computer Code," Energy, no. March, 1989.

8. E. U. C. Regulation, EU Commission Regulation 814/2013 implementing Directive 2009/125/EC of the European Parliament and of the Council with regard to ecodesign requirements for water heaters and hot water storage tanks, 2013, Brussel, 2013.

9. D. W. Abrams and A. C. Shedd, "Effect of seasonal changes in use patterns and cold inlet water temperature on water-heating loads," ASHRAE Trans., vol. 102, pp. 1038-1053, 1996. 